\title{
Glomangiopericytoma of the Nasal Cavity with CTNNB1 p.S37C Mutation: A Case Report and Literature Review
}

\author{
Michihisa Kono ${ }^{1,4} \cdot$ Nobuyuki Bandoh $^{1}$ (1) $\cdot$ Ryosuke Matsuoka ${ }^{2} \cdot$ Takashi Goto $^{1} \cdot$ Toshiaki Akahane $^{3} \cdot$ Yasutaka Kato $^{3}$. \\ Hiroshi Nakano ${ }^{3} \cdot$ Tomomi Yamaguchi $^{3} \cdot$ Yasuaki Harabuchi ${ }^{4} \cdot$ Hiroshi Nishihara $^{5}$
}

Received: 2 July 2018 / Accepted: 18 August 2018 / Published online: 11 September 2018

(c) The Author(s) 2018

\begin{abstract}
Glomangiopericytoma (GPC) is a rare mesenchymal tumor arising from the nasal cavity or paranasal sinuses. GPC was categorized as a borderline and low-malignant-potential tumor by the World Health Organization in 2005 and accounts for less than $0.5 \%$ of all sinonasal tumors. We report a case of GPC in a 74-year-old woman with a history of recurrent epistaxis and nasal obstruction. A reddish tumor was seen in the right nasal cavity. Enhanced computed tomography showed a mass lesion occupying the right nasal cavity. The tumor, which originated from the nasal septum in the olfactory fissure area, was resected with 5-mm mucosal margins by endoscopic sinus surgery. Histologic examination revealed a uniform proliferation of oval-to-short spindle-shaped cells beneath the epithelium. Immunohistologic analysis demonstrated the tumor cells were positive for $\alpha$-smooth muscle actin, $\beta$-catenin and Vimentin, and negative for AE1/AE3, Bcl-2, CD34, CD117, Factor VIIIR Ag, S-100 protein, or STAT6. The percentage of Ki-67-positive cells was approximately 5\%. Genetic analysis using next-generation sequencing revealed a missense mutation in the $C T N N B 1$ gene (c.110C $>\mathrm{G}, \mathrm{p} . \mathrm{S} 37 \mathrm{C})$. While other $C T N N B 1$ mutations have been described in GPC; this is the first report of this specific mutation. The mutation was confirmed using Sanger sequencing.
\end{abstract}

Keywords Glomangiopericytoma (GPC) $\cdot$ CTNNB1 $~$ Next-generation sequencing (NGS) · Endoscopic sinus surgery (ESS)

Electronic supplementary material The online version of this article (https://doi.org/10.1007/s12105-018-0961-z) contains supplementary material, which is available to authorized users.

Nobuyuki Bandoh

bando@hokuto7.or.jp

1 Department of Otolaryngology-Head and Neck Surgery, Hokuto Hospital, Inadacho Kisen 7-5, Obihiro 080-0833, Japan

2 Center for Diagnostic Pathology, Mita Hospital, International University of Health and Welfare, Tokyo 108-8329, Japan

3 Laboratory of Cancer Medical Science, Department of Biology and Genetics, Hokuto Hospital, Inadacho Kisen 7-5, Obihiro 080-0833, Japan

4 Department of Otolaryngology-Head and Neck Surgery, Asahikawa Medical University, Midorigaoka-Higashi 2-1-1-1, Asahikawa 078-8510, Japan

5 Keio Cancer Center, Keio University School of Medicine, 35 Shinanomachi, Shinjukuku, Tokyo 160-8582, Japan

\section{Introduction}

Glomangiopericytoma (GPC), also called sinonasal-type hemangiopericytoma, is a rare mesenchymal tumor arising from the pericytes surrounding capillaries [1]. GPC was distinguished from hemangiopericytoma and solitary fibrous tumors and categorized as a borderline and low-malignantpotential soft-tissue tumor of the nose and paranasal sinuses by the World Health Organization in 2005 [2]. GPC accounts for less than $0.5 \%$ of all sinonasal tumors. We report a case of GPC treated with endoscopic sinus surgery (ESS) and analysis of mutations in cancer-related genes using nextgeneration sequencing (NGS).

\section{Case Report}

A 74-year-old Japanese woman presented with a 1-year history of right nasal obstruction and 1-month history of epistaxis. A reddish tumor was observed in the right nasal 
cavity (Fig. 1a). Computed tomography (CT) scan showed a mass occupying the right nasal cavity with strong enhancement (Fig. 1b, c). FDG-PET/CT showed slight uptake by the tumor (Fig. 1d). We diagnosed a benign tumor of the nasal cavity and resected the mass by ESS under general anesthesia. The tumor, which originated from the nasal septum in the olfactory fissure area, was completely resected with 5-mm mucosa margins. The blood loss was $200 \mathrm{ml}$, and the operation time was $75 \mathrm{~min}$.

Histopathologic examination revealed that the tumor extended with a diffuse growth pattern beneath the epithelium (Fig. 2a). Oval-to-short spindle-shaped cells with uniform proliferation and stromal bleeding were observed
(Fig. 2b). Immunohistologic analysis showed tumor cells with cytoplasmic staining for $\alpha$-smooth muscle actin (SMA) (Fig. 2c) and Vimentin (Fig. 2d). Diffuse staining for CD99 (Fig. 2e) and nuclear staining for $\beta$-catenin (Fig. 2f) were observed. Tumor cells were not stained for STAT6 (Fig. 2g), AE1/AE3, Bcl-2, CD34, CD117, Factor VIIIR Ag, or S-100 protein (data not shown). The percentage of Ki-67-positive cells was approximately $5 \%$ (Fig. $2 \mathrm{~h}$ ). On the basis of these findings, the patient was diagnosed with GPC. Two years after the surgery, the patient is alive without local recurrence or metastasis.

Genetic analysis was performed according to the manufacturer's instructions [3]. Briefly, total DNA was extracted
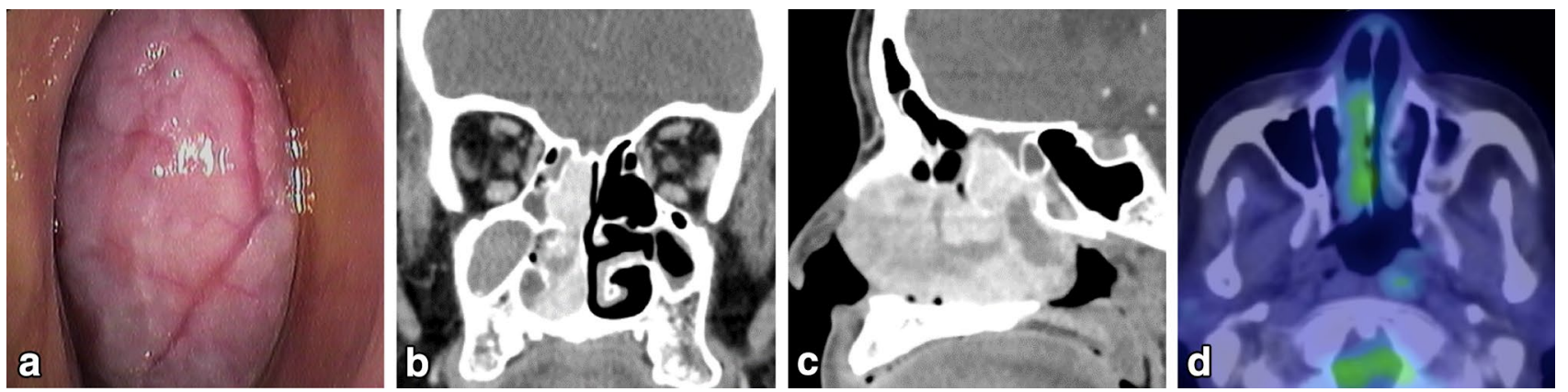

Fig. 1 Nasal endoscopic examination showed a reddish tumor in the right nasal cavity (a). CT scan revealed a mass occupying the right nasal cavity, with strong enhancement $(\mathbf{b}, \mathbf{c})$. FDG-PET/CT showed slight uptake by the tumor (d)
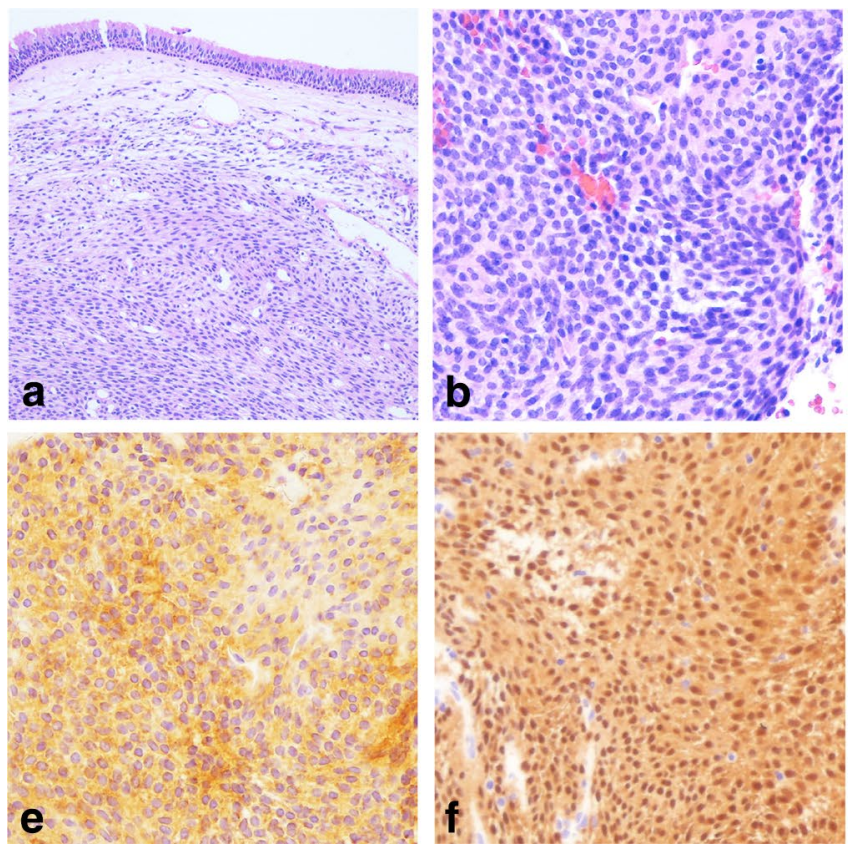

Fig. 2 Histopathologic examination revealed that the tumor extended with a diffuse growth pattern beneath the epithelium (HE, a). Ovalto-short spindle-shaped cells with uniform proliferation and stromal bleeding were observed (HE, b). Immunohistologic analysis showed tumor cells with cytoplasmic staining for $\alpha$-smooth muscle actin
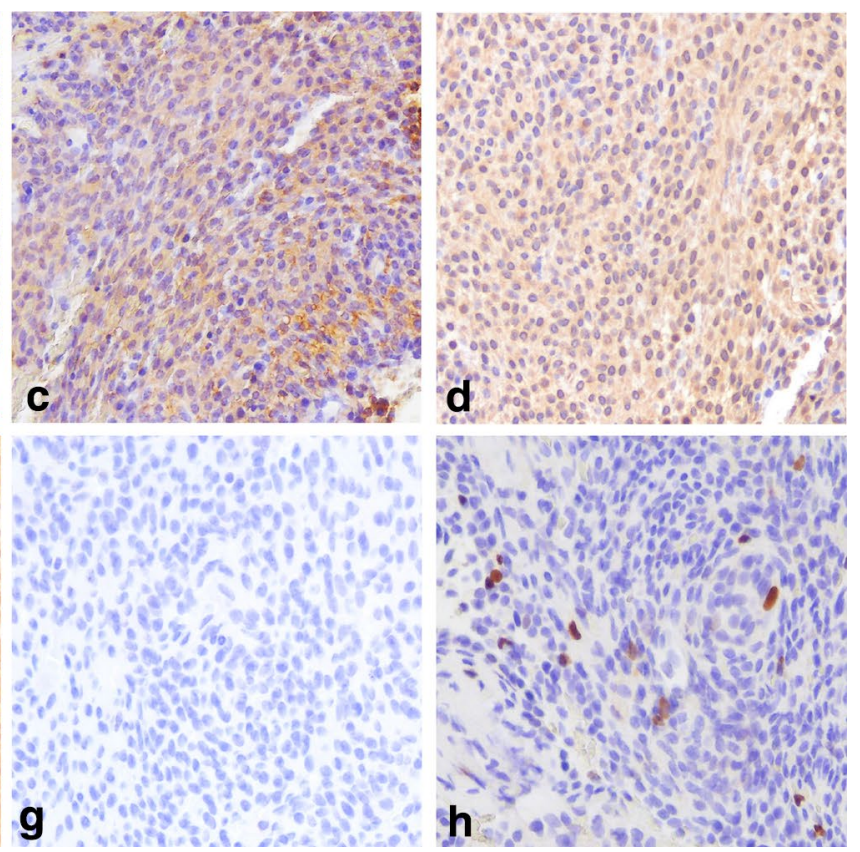

(SMA) (c) and Vimentin (d). Diffuse staining of tumor cells for CD99 (e) and nuclear staining for $\beta$-catenin (f) were observed. Tumor cells were not stained for STAT6 (g). The percentage of Ki-67-positive cells was approximately $5 \%$ (h). Magnification $\times 20(\mathbf{a}), \times 400$ (b-h) 
from 5- $\mu \mathrm{m}$-thick formalin-fixed paraffin-embedded tissue sections of the tumor and peripheral blood samples. A GeneRead DNA seq Targeted Panel V2 human comprehensive cancer panel (NGHS-501X; Qiagen, Valencia, CA) was used for amplicon sequencing of targeted regions of 160 cancer-related genes (Table S1). Libraries were sequenced using a MiSeq (Illumina, San Diego, CA). Raw read data obtained from the amplicon sequencing were processed using online analytical resources from the GeneRead DNAseq Variant Calling Service for analysis of mutations. Among the 160 cancer-related genes examined, the analysis revealed only a missense mutation in the CTNNB1 gene (c. $110 \mathrm{C}>\mathrm{G}$, p.S37C; Fig. 3a). The mutation was confirmed using Sanger sequencing (Fig. 3b).

\section{Discussion}

Characteristics of 23 patients with GPC identified from the literature published after 2005 are summarized in Table 1 [4-20]. Median age of patients with GPC was 60 years and ranged from 22 to 86 years. More patients were female (female: 16, male: 7). The most frequent clinical presentation was epistaxis in $18(78 \%)$, followed by nasal obstruction in $12(52 \%)$ and headache in $4(17 \%)$. The tumor usually appears submucosal, beefy red, soft and hemorrhagic without surface ulceration. CT invariably shows a soft-tissue mass with strong enhancement in the unilateral nasal cavity or paranasal sinuses. Tumor limited to the unilateral nasal cavity was present in $9(45 \%)$ patients. Nasal tumor extending to the ethmoid sinus was present in $9(45 \%)$ patients and to the maxillary sinus in $4(20 \%)$ of the 20 patients with detailed information. Complete surgical resection is the standard treatment in GPC because the tumor is relatively resistant to chemotherapy and radiation [7]. Surgical resection by ESS was performed in 13 (57\%) of the 23 patients. Based on tumor extension, partial resection of the maxilla [9] or external incisional surgery has been reported [4-6]. We performed ESS with 5-mm safety margins for the basal part of the tumor. Recurrence after resection has been reported in $15.1 \%$ of cases, and this can be managed by additional surgery [1]. The prognosis of GPC is usually favorable (5-year overall survival rate: $88 \%$ ); however, longterm follow-up is essential for the management of GPC [1].

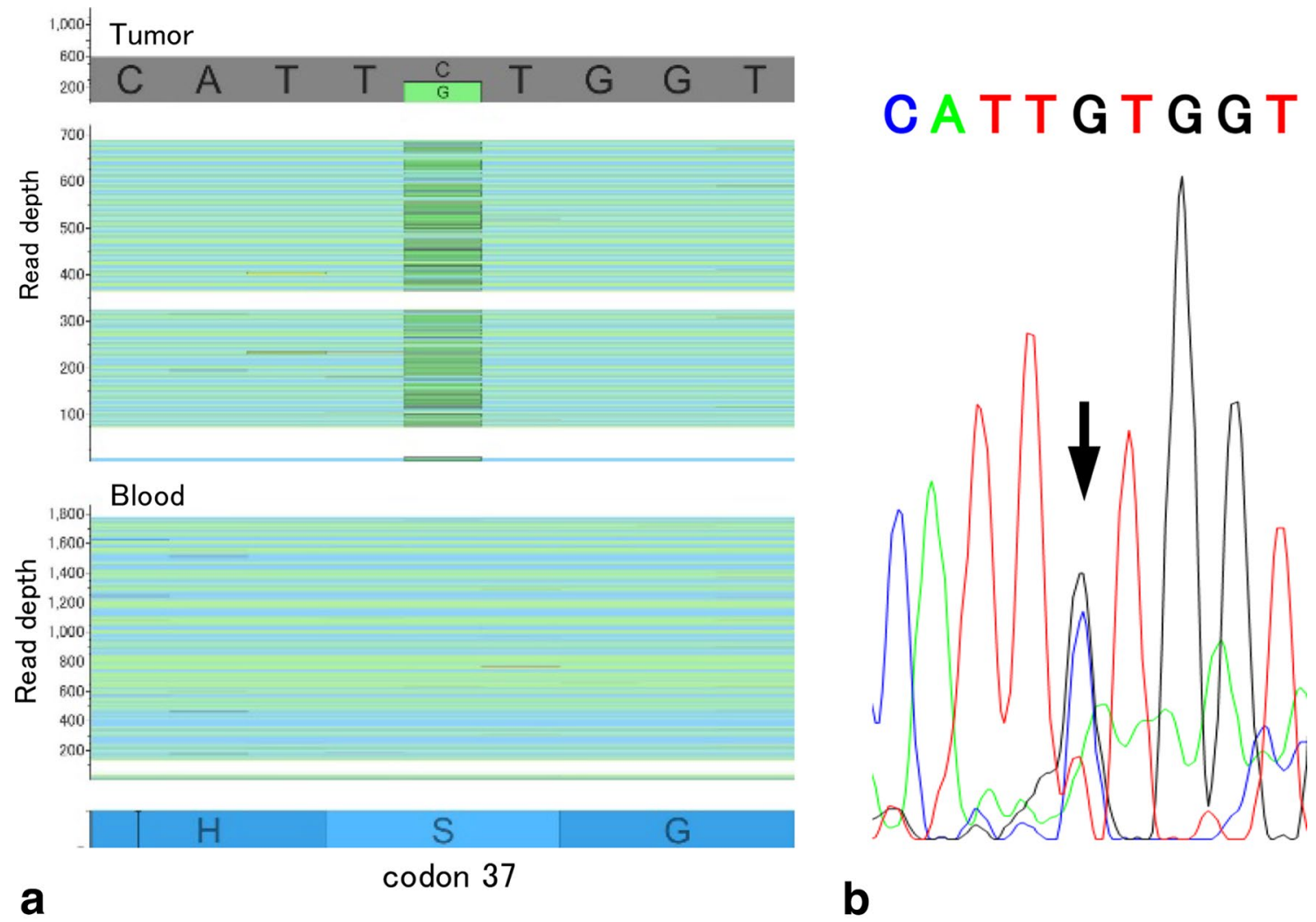

Fig. 3 Targeted genomic DNA sequences determined using nextgeneration sequencing were compared between tumor and peripheral blood samples with a read depth of 700 and 1800 , respectively. A CTNNB1 mutation was identified in exon 3 with a $\mathrm{C}$ to $\mathrm{G}$ base change at nucleotide $110($ c. $110 \mathrm{C}>\mathrm{G})$, leading to substitution of serine for cysteine at position 37 (p.S37C) of the protein product. The image was produced using the free software Golden Helix GenomeBrowse (http://goldenhelix.com) and modified (a). The mutation (c.110C > G) was confirmed using Sanger sequencing (b) 
Table 1 Characteristics of glomangiopericytoma patients reported in the literature published after 2005

\begin{tabular}{|c|c|c|c|c|c|c|}
\hline Author & Age & Gender & Symptom & Location & Surgery & $\mathrm{Ki}-67(\%)$ \\
\hline Angouridakis et al. [10] & 45 & M & Epistaxis, obstruction & $\mathrm{N}, \mathrm{E}, \mathrm{M}, \mathrm{S}$ & ESS & \\
\hline Worden et al. [11] & 78 & $\mathrm{~F}$ & Epistaxis, obstruction, rhinorrhea, headache & $\mathrm{N}$ & ESS & \\
\hline Dandekar and McHugh [4] & 48 & $\mathrm{~F}$ & Epistaxis, obstruction & $\mathrm{N}, \mathrm{E}$ & Medial maxillectomy & \\
\hline Higashi et al. [12] & 60 & M & Epistaxis, obstruction & $\mathrm{N}$ & ESS & \\
\hline Oosthuizen et al. [14] & 32 & $\mathrm{~F}$ & $\begin{array}{l}\text { Epistaxis, obstruction, anosmia, headache, } \\
\text { proptosis }\end{array}$ & $\mathrm{N}, \mathrm{E}, \mathrm{S}, \mathrm{A}$ & ESS & $<1$ \\
\hline Arpaci et al. [13] & 68 & $\mathrm{~F}$ & Obstruction, headache, hyposmia & $\mathrm{N}$ & ESS & \\
\hline Jung et al. [5] & 42 & $\mathrm{~F}$ & Epistaxis & $\mathrm{N}, \mathrm{E}, \mathrm{O}$ & ESS + External incision & \\
\hline Verim et al. [16] & 72 & $\mathrm{~F}$ & Epistaxis, obstruction & $\mathrm{N}$ & ESS & \\
\hline Lee et al. [15] & 60 & $\mathrm{~F}$ & Osteomalacia & M & Caldwell-Luc & \\
\hline Gokdogan et al. [17] & 32 & M & Epistaxis, obstruction & N, E, M, S & ESS & \\
\hline Roy et al. [18] & 60 & $\mathrm{~F}$ & Epistaxis, obstruction & $\mathrm{N}, \mathrm{E}$ & ESS & \\
\hline Handra-Luca et al. [22] & 86 & $\mathrm{~F}$ & Obstruction & $\mathrm{N}$ & Resection & 5 \\
\hline Zielinska-Kazmiersk et al. [5] & 80 & M & Epistaxis, obstruction & $\mathrm{N}, \mathrm{M}$ (bil) & External incision & 2 \\
\hline Psoma et al. [7] & 55 & M & Obstruction & $\mathrm{N}, \mathrm{E}$ & ESS & \\
\hline Oliveira et al. [19] & 60 & $\mathrm{~F}$ & Epistaxis, obstruction & $\mathrm{N}, \mathrm{E}, \mathrm{O}, \mathrm{A}$ & ESS & \\
\hline Kim et al. [20] & 82 & $\mathrm{~F}$ & Epistaxis, rhinorrhea, headache & $\mathrm{N}$ & ESS & \\
\hline Kim et al. [20] & 57 & $\mathrm{~F}$ & Pain & $\mathrm{N}$ & Resection & \\
\hline Anzai et al. [8] & 68 & M & Epistaxis & $\mathrm{N}$ & ESS & $<5$ \\
\hline Al Saad et al. [9] & 22 & $\mathrm{~F}$ & Epistaxis & $\mathrm{N}, \mathrm{M}, \mathrm{H}$ & Partial resection of maxilla & \\
\hline Suzuki et al. [24] & 81 & M & Epistaxis & Unknown & Resection & $<1$ \\
\hline Suzuki et al. [24] & 62 & $\mathrm{~F}$ & Epistaxis & Unknown & Resection & 1 \\
\hline Suzuki et al. [24] & 81 & $\mathrm{~F}$ & Epistaxis & Unknown & Resection & 2 \\
\hline Present case & 74 & $\mathrm{~F}$ & Epistaxis, obstruction & $\mathrm{N}$ & ESS & 5 \\
\hline
\end{tabular}

$N$ nasal cavity, $E$ ethmoid sinus, $M$ maxillary sinus, $S$ sphenoid sinus, $O$ orbita, $A$ anterior skull base, $H$ hard palate, bil bilateral

GPC is diagnosed by characteristic histology showing epithelioid cells in a perivascular pattern with frequent perivascular hyalinization. Tumor cells are immunohistologically positive for cytoplasmic SMA and Vimentin, and nuclear $\beta$-catenin in $80-100 \%$. Tumor cells exhibit no strong diffuse staining for $\mathrm{CD} 34$ and are basically negative for AE1/ AE3, Bcl-2, CD34, CD99, CD117, Factor VIIIR Ag, S-100 protein, and STAT6 $[1,21]$. Some reports demonstrated that tumor cells were positive for CD99 in agreement with our result [22]. High Ki-67 index ( $>10 \%)$ is a prognostic factor for aggressive behavior $[1,21]$, although $5 \%$ was the highest index in the 8 patients analyzed (Table 1). Nuclear staining for $\beta$-catenin is reported to be a diagnostic marker of GPC [21, 23]; however, there are only 4 reports describing mutations in the CTNNB1 gene as well as nuclear $\beta$-catenin expression in GPC $[8,21,23,24]$. Mutations in the aminoterminal region of $C T N N B 1$ gene, which encodes $\beta$-catenin, activate the Wnt-signaling pathway. After activation, $\beta$-catenin is stabilized by phosphorylation and translocates to the nucleus. The accumulation of $\beta$-catenin in the nucleus activates transcriptional factors, promoting tumorigenesis and proliferation of tumor cells [23]. To date, 23 types of mutation in the CTNNB1 gene in GPC have been described
(Fig. 4) $[8,21,23,24]$. All of the CTNNB1 mutations, including that identified in the present case, involve a singlebase substitution in exon 3. Eight (35\%) of the 23 mutation (No. of mutation)

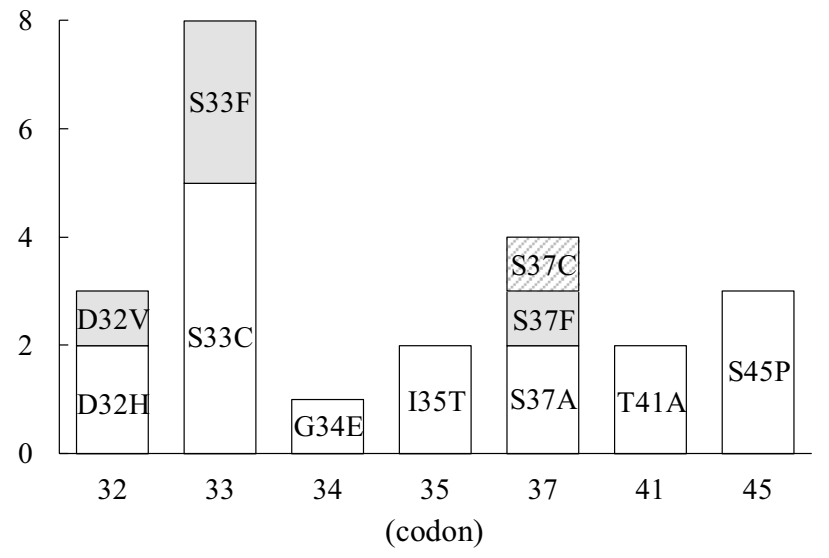

Fig. 4 Twenty-three reported types of mutation in the CTNNB1 gene in cases of glomangiopericytoma as reported by Lacosta et al. [21], Haller et al. [23], Anzai et al. [8], and Suzuki et al. [24]. Mutations were combined with that identified in the present case and shown as a bar graph. One patient reported by Haller et al. harbored two mutations (p.G34E and p.S37F) 
types occur at codon 33. Four mutation types (19\%) occur at codon 37, including 2 p.S37A, 1 p.S37F, and 1 p.S37C mutation. The CTNNB1 p.S37C (c.110C > G) mutation we detected has not been observed in previous reports regarding GPC. The p.S37C mutation accounts for only $2.8 \%$ of all 6939 CTNNB1 mutations analyzed in various mesenchymal and epithelial neoplasms, including hepatocellular, endometrial, ovarian, and pituitary tumors, according to COSMIC (April 2018). NGS is an increasingly important method for detecting mutations in cancer-related genes, as it can be used to simultaneously test for multiple mutations of interest in a short period. Targeted NGS is more cost efficient and faster than previous sequencing methods. We analyzed 160 cancerrelated genes for mutations in just 2 days using NGS and detected only one mutation in the CTNNB1 gene.

Differential diagnosis of GPC should be made to distinguish the tumor from solitary fibrous tumors (hemangiopericytoma), glomus tumors, desmoid-type fibromatosis, and nasopharyngeal angiofibroma [2]. Solitary fibrous tumors are characterized by chromosomal translocation resulting in the formation of a NAB2-STAT6 fusion gene. Nuclear staining of STAT6 resulting from the translocation of the NAB2-STAT6 fusion protein to the nucleus is a gold-standard marker for the tumor [8]. GPC is immunohistologically negative for STAT6 and NAB2-STAT6 fusion gene transcripts [25]. Glomus tumors and GPC exhibit many histologic and immunohistologic similarities, including the perivascular histologic pattern and SMA expression [1]. However, glomus tumors lack $\beta$-catenin nuclear expression and CTNNB1 mutations [26]. Fibroblastic neoplasms such as nasopharyngeal angiofibroma and desmoid-type fibromatosis exhibit nuclear $\beta$-catenin expression and CTNNB1 mutations; however, these tumors are histologically different from GPC [21]. Thus, genetic analysis of oncogenes by NGS is useful for distinguishing vascular neoplasms originating from the head and neck region.

\section{Conclusion}

We reported a rare case of GPC successfully treated with ESS. A CTNNB1 p.S37C mutation was detected by NGS and Sanger sequencing methods, and it was the first report of this specific mutation.

Acknowledgements The authors would like to thank FORTE Scientific Communications (http://www.forte-science.co.jp) for editing a draft of this manuscript.

Author Contributions MK, NB and TG performed surgery and provided bedside care. TA, YK, HN, and TY performed mutational analyses. RM and HN performed pathologic diagnosis. YH conceived the study design. MK and NB drafted the manuscript. All authors approved the final version of the manuscript.

\section{Compliance with Ethical Standards}

Conflict of interest The authors declare that there are no actual or potential conflicts of interest in relation to this article.

Ethical Approval All procedures performed on patient tumor samples in this study were in accordance with the ethical standards of the Institute Ethics Committee and the 1964 Helsinki declaration and its later amendments or comparable ethical standards.

Informed Consent Written informed consent for publication of clinical details and images was obtained from the patient and her family.

Open Access This article is distributed under the terms of the Creative Commons Attribution 4.0 International License (http://creativeco mmons.org/licenses/by/4.0/), which permits unrestricted use, distribution, and reproduction in any medium, provided you give appropriate credit to the original author(s) and the source, provide a link to the Creative Commons license, and indicate if changes were made.

\section{References}

1. Thompson LD, Miettinen M, Wenig BM. Sinonasal-type hemangiopericytoma: a clinicopathologic and immunophenotypic analysis of 104 cases showing perivascular myoid differentiation. Am J Surg Pathol. 2003;27:737-49.

2. Thompson LD, Fanburg-Smith J, Wenig B. Tumours of the nasal cavity and paranasal sinuses. Borderline and low malignant potential tumours of soft tissue. In: Barnes L, Eveson JW, Reichart P, Sidransky D, editors. World Health Organization (WHO) classification of tumours. Vol. 9. Pathology and genetics of head and neck tumours. Lyon: IARC Press; 2005. pp. 43-4.

3. Ellison G, Huang S, Carr H, Wallace A, Ahdesmaki M, Bhaskar S, et al. A reliable method for the detection of BRCA1 and BRCA2 mutations in fixed tumour tissue utilising multiplex PCR-based targeted next generation sequencing. BMC Clin Pathol. 2015. https://doi.org/10.1186/s12907-015-0004-6.

4. Dandekar M, McHugh JB. Sinonasal glomangiopericytoma: case report with emphasis on the differential diagnosis. Arch Pathol Lab Med. 2010;134:1444-9.

5. Jung ES, Yang SW, Kim JH, Kim SW. A case of glomangiopericytoma involving the orbital wall. Ear Nose Throat J. 2013;92:E13-5.

6. Zielinska-Kazmierska B, Grodecka J, Teodorczyk-Werfel D, Milcarz R. The midfacial glomangiopericytoma - case report. J Oral Biol Craniofac Res. 2015;5:124-6.

7. Psoma E, Karkos PD, Dova S, Gavriilidis M, Markou K, Kouskouras C, et al. Sinonasal glomangiopericytoma treated with preoperative embolisation and endoscopic sinus surgery. Ecancermedicalscience. 2016. https://doi.org/10.3332/ecancer.2016.692.

8. Anzai T, Saito T, Tsuyama S, Toh M, Ikeda K, Ito S. A case of glomangiopericytoma at the nasal septum. Head Neck Pathol. 2017:https://doi.org/10.1007/s12105-017-0870-6.

9. Al Saad S, Al Hadlaq R, Al-Zaher N. Glomangiopericytoma (Hemangiopericytoma) of the maxillary sinus and sinonasal tract. Hematol Oncol Stem Cell Ther. 2017;10:96-8.

10. Angouridakis N, Zaraboukas T, Vital J, Vital V. Sinonasal hemangiopericytoma of the middle turbinate: a case report and brief review of the literature. B-ENT. 2007;3:139-43.

11. Worden B, Getz A, Luo R, Hwang PH. Pathology quiz case 1. Glomangiopericytoma (sinonasal-type hemangiopericytoma 
[HPC]). Arch Otolaryngol Head Neck Surg. 2009. https://doi. org/10.1001/archoto.2009.37-a.

12. Higashi K, Nakaya K, Watanabe M, Ikeda R, Suzuki T, Oshima $\mathrm{T}$, et al. Glomangiopericytoma of the nasal cavity. Auris Nasus Larynx. 2011;38:415-7.

13. Arpaci RB, Kara T, Vayisoglu Y, Ozgur A, Ozcan C. Sinonasal glomangiopericytoma. J Craniofac Surg. 2012;23:1194-6.

14. Oosthuizen JC, Kennedy S, Timon C. Glomangiopericytoma (sinonasal-type haemangiopericytoma). J Laryngol Otol. 2012;126:1069-72.

15. Lee GG, Dhong HJ, Park YS, Ko YH. Sinonasal glomangiopericytoma causing oncogenic osteomalacia. Clin Exp Otorhinolaryngol. 2014;7:145-8.

16. Verim A, Kalaycik Ertugay C, Karaca CT, Gunes P, Sheidaei S, Oysu C. A rare tumor of nasal cavity: glomangiopericytoma. Case Rep Otolaryngol. 2014. https://doi.org/10.1155/2014/282958.

17. Gokdogan O, Demirhan B, Koybasioglu A, Ileri F. An unusual mass of nasal cavity: recurrent glomangiopericytoma. Kulak Burun Bogaz Ihtis Derg. 2015;25:240-4.

18. Roy NP, Desai DP, Jain SA. Glomangiopericytoma of nasal cavity. Indian J Pathol Microbiol. 2015;58:554-6.

19. Oliveira VM, Neto Almeida G, Silva DR, Escada PA. Endoscopic resection of invasive glomangiopericytoma following preoperative embolisation. BMJ Case Rep. 2016. https://doi.org/10.1136/ bcr-2015-213423.

20. Kim J, Jeon J, Kim DH, Park ES, Maeng LS, Jun SY. Glomangiopericytoma and glomus tumor of the sinonasal tract: a report of two cases with emphasis on the differential diagnosis. Pathol Int. 2016;66:348-50.

21. Lasota J, Felisiak-Golabek A, Aly FZ, Wang ZF, Thompson LD, Miettinen M. Nuclear expression and gain-of-function betacatenin mutation in glomangiopericytoma (sinonasal-type hemangiopericytoma): insight into pathogenesis and a diagnostic marker. Mod Pathol. 2015;28:715-20.

22. Handra-Luca A, Abd Elmageed ZY, Magkou C, Lae M. Immunophenotype heterogeneity in nasal glomangiopericytoma. Case Rep Otolaryngol. 2015. https://doi.org/10.1155/2015/308743.

23. Haller F, Bieg M, Moskalev EA, Barthelmess S, Geddert H, Boltze $\mathrm{C}$, et al. Recurrent mutations within the amino-terminal region of beta-catenin are probable key molecular driver events in sinonasal hemangiopericytoma. Am J Pathol. 2015;185:563-71.

24. Suzuki Y, Ichihara S, Kawasaki T, Yanai H, Kitagawa S, Shimoyama Y, et al. $\beta$-catenin (CTNNB1) mutation and LEF1 expression in sinonasal glomangiopericytoma (sinonasal-type hemangiopericytoma). Virchows Arch. 2018. https://doi.org/10.1007/s0042 8-018-2370-9.

25. Chmielecki J, Crago AM, Rosenberg M, O'Connor R, Walker SR, Ambrogio L, et al. Whole-exome sequencing identifies a recurrent NAB2-STAT6 fusion in solitary fibrous tumors. Nat Genet. 2013;45:131-2.

26. Agaimy A, Barthelmess S, Geddert H, Boltze C, Moskalev EA, Koch M, et al. Phenotypical and molecular distinctness of sinonasal haemangiopericytoma compared to solitary fibrous tumour of the sinonasal tract. Histopathology. 2014;65:667-73. 